\title{
NEWS ANALYSIS
}

\section{Covid-19: Lateral flow tests in care homes failed to stop outbreaks, finds study}

\section{Rapid testing's limitations are becoming evident from wider use in the community, reports Elisabeth Mahase}

\section{Elisabeth Mahase}

Lateral flow tests did not reduce the number or scale of covid-19 outbreaks in England's care homes and caused excessive workload for staff, concludes research on the effects of testing staff and visitors. ${ }^{1}$

The preprint, made available through the Social Science Research Network, compared outbreaks in care homes that piloted the rapid tests in Liverpool with those in homes in the same area that weren't in the pilot. The research, commissioned by the Department of Health and Social Care, and which has not yet been peer reviewed, found that six of the 11 pilot homes had outbreaks of covid-19 and that only one had a positive result from lateral flow testing before the outbreak.

Staff were tested twice a week with self administered Innova rapid tests, while visitors were required to provide the care home with two negative rapid test results, taken within 24 hours, before they visited. The research team, which included one researcher who works with AstraZeneca, interviewed staff and found that testing protocol adherence was poor, with just $8.6 \%$ of staff achieving more than $75 \%$ adherence to protocol and $25.3 \%$ achieving more than or equal to $50 \%$.

"The combination of lateral flow tests and PCR [polymerase chain reaction] tests on a regular basis increased pressure on staff, adding to an already saturated workflow," the team said. "A disconnect exists between the prescribed testing regime and the 'real-life' context of use.

"Failure to address this disconnect between testing regimes and the care home workforce risks an increase in staff dissatisfaction and its attendant potential for increased staff turnover and burnout."

Martin Green, chief executive officer of Care England, the representative body for care services, said, "Rapid, reliable covid-19 testing is not only vital but a key part of the infection control measures that care homes have put in place to protect their residents and staff ... We need to look at the study, which is based on a small number of homes, and see what learning and messages the Department of Health and Social Care will be communicating."

A spokesperson for the department said, "We remain committed to the use of these rapid lateral flow devices in care homes, and we are in touch with care homes with lower take-up rates to provide additional support."
Age UK's director, Caroline Abrahams, said, “This new study is not the first to question the reliability of these tests, but we must remember that they are simply 'one tool in the box.' Excellent infection control is equally if not more important in keeping everyone safe, and it's down to the government to ensure every care home has the funding and staff numbers to do it well, now and into the future. For the sake of older people's happiness and wellbeing we desperately need regular in-person visiting to be happening in every care home again.

"Ultimately the pandemic has shone a light on our broken social care system, so 2021 must be the year in which the prime minister keeps his promise to fix care, once and for all.”

\section{Community testing}

Meanwhile another preprint, provided through medRxiv, modelled how many positive cases picked up through PCR testing as part of the contact tracing system could have been detected with rapid tests. ${ }^{2}$ It reported that the "most and least sensitive lateral flow tests would detect $89.5 \%$ [95\% confidence interval $89.4 \%$ to $89.6 \%$ ] and $83.0 \%$ [82.8\% to $83.1 \%$ ] of cases with PCR-positive contacts, respectively."

The research was carried out by a team from the health department, Public Health England, and the University of Oxford, including John Bell, regius professor of medicine. Although the team declared no conflicts of interests, Bell has caused some controversy over his alleged "long list" of financial interests that remain undisclosed. ${ }^{3}$

The team said that while lateral flow tests could not replace PCR for all people with covid symptoms, they could help to identify infected people who would otherwise not have been tested, such as those without symptoms.

Jon Deeks, the professor of biostatistics who leads Cochrane's covid-19 test evaluation activities and has been a vocal critic of the lateral flow test roll-out, said a sensible use of these tests would be to deploy them alongside PCR in testing centres, so people would take both tests at the same time. This would enable contact tracing to begin "straight away, removing that three day waiting period" for people who test positive in the rapid test, while still ensuring that additional cases were picked up by the PCR test.

"In a test and trace sense it's a really good idea," he said. However, Deeks warned against using lateral 
flow tests as a replacement for PCR, especially in asymptomatic people, and said a negative rapid test result should certainly not be used to rule out infection.

A Cochrane review of lateral flow tests found that they were better at identifying covid-19 infection in people with symptoms than in those without, ${ }^{4}$ while an evaluation of the main test used in the UK, the Innova test, found that its sensitivity was $79 \%$ when performed by laboratory scientists. However, this fell to $73 \%$ when it was carried out by trained healthcare staff and 58\% for self-trained members of the public, meaning when used by the public the test can miss nearly half of cases. ${ }^{5}$

The Innova test is being used in the UK as part of the mass testing scheme for asymptomatic people, such as in schools. This testing scheme has now been expanded across the whole population of England, with the public told they can order two rapid tests every week. ${ }^{6}$

\section{False positives}

While concern over the accuracy of negative results from these tests is not new, fears over numbers of false positives have been growing.

Public Health England has reported that more than 26 million lateral flow tests were taken between 8 March and 4 April. Around half of the 30904 positive results identified were followed up with a PCR test, of which 3034 (18\%) came back negative. ${ }^{7}$

Emails leaked to the Guardian indicated that these rapid tests could be scaled back in England because of fears over false positive results. In one email an adviser to health secretary, Matt Hancock, emphasised the "fairly urgent need for decisions" on "the point at which we stop offering asymptomatic testing." 8 The adviser added that currently someone in London who received a positive lateral flow result had "at best a $25 \%$ chance of it being a true positive."

This is because the likelihood of a positive result being wrong increases when infection rates are low, as the tests produce roughly the same number of false positives as in high rate areas.

In response a health department spokesperson said, “There are no plans to halt the universal programme... Rapid testing detects cases quickly, meaning positive cases can isolate immediately, and figures show that for every 1000 lateral flow tests carried out, there is fewer than one false positive result."

1 Enhanced Lateral Flow Testing Strategies in Care Homes Are Associated with Poor Adherence and Were Insufficient to Prevent COVID-19 Outbreaks. Results from a Mixed Methods Implementation Study. SSRN, 8 April 2021 https://papers.ssrn.com/sol3/papers.cfm?abstract_id $=3822257$.

2 SARS-CoV-2 infectivity by viral load, $S$ gene variants and demographic 2 factors and the utility of lateral flow devices to prevent transmission. MedRxiv. https://www.medrxiv.org/content/10.1101/2021.03.31.21254687v1.full.pdf.

3 Thacker PD. Tracking down John Bell: how the case of the Oxford professor exposes a transparency crisis in government. BMJ2021;372:n490. doi: 10.1136/bmj.n490 pmid: 33622805

4 Griffin S. Covid-19: Lateral flow tests are better at identifying people with symptoms, finds Cochrane review. BMJ2021;372:n823. doi: 10.1136/bmj.n823 pmid: 33766893

5 Mahase E. Covid-19: Innova lateral flow test is not fit for "test and release" strategy, say experts. BM/2020;371:m4469. doi: 10.1136/bmj.m4469. https://www.bmj.com/content/371/bmj.m4469\#: :text=|t\%20found\%20an\%20overall\%20sensitivity,(22\%2F6967\%20tests.).

6 lacobucci G. Covid-19: Government rolls out twice weekly rapid testing to all in England. BMJ 2021;373:n902. https://www.bmj.com/content/373/bmj.n902. doi: 10.1136/bmj.n902 pmid: 33824178

7 Covid: $82 \%$ of positive rapid tests 'were correct'. BBC. 15 April 2021 https://www.bbc.co.uk/news/health-56750460.

8 Halliday J. Rapid Covid testing in England may be scaled back over false positives. Guardian. 15 Apr 2021. https://www.theguardian.com/world/2021/apr/15/rapid-covid-testing-in-england-maybe-scaled-back-over-false-positives.
This article is made freely available for use in accordance with BMJ's website terms and conditions for the duration of the covid-19 pandemic or until otherwise determined by BMJ. You may use, download and print the article for any lawful, non-commercial purpose (including text and data mining) provided that all copyright notices and trade marks are retained. 